\title{
Infinitely many periodic solution for second-order perturbed damped vibration systems
}

\author{
Khachnaoui Khaled ${ }^{1}$ \\ ${ }^{1}$ Universite de Kairouan
}

October 21, 2020

\begin{abstract}
In this paper, a class of perturbed damped vibration system is considered. By using variational methods, we obtain some new criteria for guaranteeing the existence of infinity many periodic solutions by the Bolle's perturbation method. These results improve the related ones in the literature.
\end{abstract}

\section{Hosted file}

Boll perturbation.pdf available at https://authorea.com/users/369219/articles/488142infinitely-many-periodic-solution-for-second-order-perturbed-damped-vibration-systems 